\title{
Kursbuch
}

\section{Revolte 2020}

Hannah Lühmann Brief einer Leserin - Adrian Lobe Like the dislike - Jasmin Siri SPD: Revoluzzer, Lampenputzer • Marc Winkelmann Bambule - Armin Nassehi Das große Nein - Hedwig Richter Sind Frauen die besseren Revolutionäre? - Anja Dilk Molli - Wolfgang Schmidbauer Die heilige Johanna des Weltbrandes - Gerhard Seyfried Von Zwille bis Hering - Karl Bruckmaier Weiß-blau ist bairisch, und grün scheißt die Gans - Astrid Séville Das Märchen vom Widerstand - Boris Groys Die totale Souveränität • Gert Heidenreich Schwarze Nullen - Heike Littger Zorro • Cornelia Koppetsch "lch denke oft an Piroschka • Christina Behler Paradise Lost $•$ Peter Felixberger FLXX 
Kursbuch 200

Revolte 2020 


\section{(D) Klimaneutral \\ Druckprodukt \\ ClimatePartner.com/12752-1803-1001}

Zum Ausgleich für die entstandene $\mathrm{CO}_{2}$-Emission bei der Produktion dieses Buches unterstützen wir die Erhaltung und Wiederaufforstung des KibaleNationalparks in Uganda. Das Projekt trägt zum Klimaschutz bei, indem die Bäume bei der Fotosynthese Kohlenstoff aus der Luft binden, es schützt die Biodiversität des tropischen Waldes und sichert 260 Arbeitsplätze.

Das Kursbuch erscheint viermal im Jahr.

Das Heft kostet einzeln $€ 19$,-

Das Jahresabo (4 Ausgaben) kostet $€ 60$,-

Im Internet: https://kursbuch.online

Kursbuch Kulturstiftung gGmbH

Miramar-Haus, Schopenstehl 15, 20095 Hamburg

Tel.: $040 / 398083-0$

V.i.S.d.P.: Peter Felixberger

(c) 2019 Kursbuch Kulturstiftung gGmbH, Hamburg

Alle Rechte für sämtliche Beiträge, auch der Übersetzung und der Wiedergabe durch Funk- und Fernsehsendungen und alle elektronischen Übermittlungen, vorbehalten.

Der Verlag weist ausdrücklich darauf hin, dass er, sofern dieses Buch externe Links enthält, diese nur bis zum Zeitpunkt der Buchveröffentlichung einsehen konnte. Auf spätere Veränderungen hat der Verlag keinerlei Einfluss. Eine Haftung des Verlags ist daher ausgeschlossen.

ISBN 978-3-96196-099-6

ISSN $0023-5652$

Herstellung und Gestaltung: Murmann Publishers GmbH, Hamburg

Druck: Steinmeier GmbH \& Co. KG, Deiningen

Printed in Germany

Zuschriften bitte per Mail an: kursbuch@kursbuch.online

Abonnenten-Service: abonnements@kursbuch.online

Pressevertrieb: PressUp GmbH, Wandsbeker Allee 1, 22041 Hamburg. www.pressup.de 